SHORT REPORT

\title{
Risk factors associated with failure of syndromic treatment of sexually transmitted diseases among women seeking primary care in Addis Ababa
}

\author{
D Wolday, Z G-Mariam, Z Mohammed, H Meles, T Messele, W Seme, A Geyid, S Maayan
}

Sex Transm Infect 2004;80:392-394. doi: 10.1136/sti.2003.005660

\begin{abstract}
Objective: To determine risk factors associated with the failure of syndromic management of sexually transmitted diseases (STDs) among women seeking treatment in primary healthcare centre in Addis Ababa, Ethiopia.

Methods: Women with symptomatic STDs seeking care in a health centre were prospectively enrolled. A total of 259 women were interviewed and underwent clinical examination; 106 were enrolled and received syndromic STD treatment and $91 \%$ returned for follow up. Logistic regression analysis was used to identify risk factors associated with treatment failure.

Results: Of the 106 women enrolled and presenting with symptomatic STDs $67 \%$ were HIV seropositive. Syndromic STD treatment did not result in clinical improvement in $30 \%$ of the women. Having genital ulcer disease, genital ulcer disease with genital discharge, genital warts, bacterial vaginosis and plasma HIV-1 load $>10000$ copies RNA/ml or being HIV seropositive were all significantly associated with treatment failure. In multivariate analysis, however, only genital ulcer disease was significantly associated with treatment failure.

Conclusion: In our setting, the association between HIV and genital ulcer disease caused by herpes may, therefore, be the reason for the failure of treatment.
\end{abstract}

$\mathrm{E}$ hiopia has one of the highest HIV prevalences in subSaharan Africa. HIV prevalence is between 14\% and 20\% among urban pregnant women, $12 \%$ in patients treated for STDs, and $74 \%$ in commercial sex workers. ${ }^{12}$ The World Health Organization (WHO) recommends syndromic treatment of STDs in developing countries at the primary healthcare level. ${ }^{3}$ However, the effectiveness of syndromic treatment approach for STDs in Ethiopia has not been validated. Indeed, the performance outcome of the syndromic STD treatment in Addis Ababa City has been characterised by low sensitivity and specificity. ${ }^{4}$ In this study, we assessed risk factors associated with the failure of syndromic treatment of STDs.

\section{PATIENTS AND METHODS Study population}

Study subjects were recruited at Tekle-Haymanot Health Centre in Addis Ababa, Ethiopia, between June and September 2001. The health centre serves a heterogeneous urban population in the centre of the city. Demographic characteristics, sexual history, and other relevant information were collected. Subjects were eligible for the study if they presented with symptoms suggestive of STDs, such as genital discharge or ulcers, and if they had had no antibiotic treatment for at least 2 weeks before enrolment. All women presenting with symptomatic STDs were offered voluntary HIV counselling and testing. The project was approved by institutional and national ethical committees.

Gynaecological examination was performed at entry visit and after syndromic STD treatment. During the speculum examination, cervical and vaginal secretions were collected for microbiological investigations. Blood was obtained for virological and immunological assays. At entry, women with clinical signs of STDs were treated based on a syndromic approach. A programme to improve syndromic case management in 18 Addis Ababa health centres was launched by the regional health bureau in collaboration with the nongovernmental organisation Médecins Sans Frontières, Belgium. ${ }^{5}$ The protocol was adopted based on the WHO syndromic treatment algorithm. ${ }^{3}$ Under the programme, drugs are dispensed in the form of pre-packaged treatments, known as syndrome selective packaging. The packet contained the full course treatment for a STD syndrome, condoms, instruction leaflet, and a partner referral card.

Women with genital discharge syndrome, and a negative risk assessment were treated with metronidazole (single oral dose $2 \mathrm{~g}$ ) and nystatin (intravaginal 100000 IU for 14 days). Those with genital discharge, but a positive risk assessment (age $<20$ years, partner with STD, having multiple sexual partners), were treated additionally with doxycycline (oral $200 \mathrm{mg}$ divided in two doses for 7 days) and spectinomycin (2 g single intramuscular injection). Women presenting with genital ulcer disease were treated with benzanthine benzylpenicillin (single intramuscular injection) and erythromycin ( $1.5 \mathrm{~g}$ divided in three doses daily for a total of 7 days). Patients were checked, on average, 2 weeks after syndromic treatment to assess compliance and clinical outcome. Treatment failure was defined when women have persistence of the symptoms and have clinical signs of genital infections at follow up visit despite treatment. Women who did not improve after syndromic treatment and those with infections that were not recognised at enrolment received pathogen specific treatment, and were asked to return 2 weeks following re-treatment.

\section{Laboratory investigations}

HIV test was performed by HIVSPOT and enzyme immunoassay (EIA). Positive specimens were confirmed by western blot. Plasma HIV-1 load was quantified by nucleic acid based amplification assay. HIV levels below the lower detection limit of the assay were considered at 80 copies $/ \mathrm{ml}$. CD4+ count was determined by FACScan.

In addition to the syndromic diagnosis of STDs, pathogen specific diagnosis of certain STDs was performed. Serology

Abbreviations: RPR, rapid plasma reagin; TPPA, Treponema pallidum passive particle agglutination 
for syphilis was done using rapid plasma reagin (RPR) test and Treponema pallidum passive particle agglutination (TPPA) assay. Those reactive to both were considered as having active syphilis. Neisseria gonorrhoeae was detected by Gram stain confirmed by culture (modified Thayer-Martin medium), and by ligase chain reaction. $C$ trachomatis was detected by ligase chain reaction. $T$ vaginalis was detected by wet mount and/or by culture using In Pouch TV and bacterial vaginosis was detected by quantitative morphology of Gram stained slides based on Nugent's criteria. ${ }^{6}$

\section{Statistical analyses}

Proportions were compared using the $\chi^{2}$ test or Fisher's exact test where appropriate. Median CD4 counts and HIV load between the different groups were compared using MannWhitney $U$ test. Univariate logistic regression analysis was used to identify predictors of increased likelihood of treatment failure. Multivariate logistic regression was used to ascertain whether associations persisted after adjustment for confounding factors. A p value of less than 0.05 was considered statistically significant.

\section{RESULTS}

Of the total of 259 women screened, 128 (49\%) did not have symptomatic STDs on presentation. Of the remaining 131 women, eight did not come for enrolment, six were excluded because of advanced AIDS, five were not willing to undergo HIV testing, six were excluded because of extensive tuberculosis, gynaecological malignancies and hysterectomy. A total of $106(81 \%)$ women were enrolled. The age of the women ranged from 17 to 51 years (median, 27) and 71 (67\%) were HIV-1 seropositive. The most common syndrome was genital discharge and bacterial vaginosis was common in this population. The syndromic diagnosis, however, either missed or led to overdiagnosis of many of the infections (table 1).

The median time of follow up was 17 (interquartile range, 15-19) days after completion of treatment. Of the 106 women enrolled, $91 \%$ returned for a follow up visit and $95 \%$ of them reported taking all the medications prescribed. Overall, syndromic STD treatment did not result in clinical improvement in $30 \%$ of the women. While treatment failure was only $14 \%$ among the 29 HIV seronegative women, it was 37\% among the 67 HIV seropositive women. Having genital ulcer disease, genital ulcer disease with genital discharge, genital warts, bacterial vaginosis, and plasma HIV-l load >10 000 copies $\mathrm{RNA} / \mathrm{ml}$ or being HIV seropositive were all significantly associated with treatment failure (table 2). In contrast, genital discharge, cervicitis, Neisseria gonorrhoeae, Candida albicans, syphilis, presence of leucocytes in cervix, or CD4 cell decrease were not associated with treatment failure. In multivariate analysis, however, only genital ulcer disease was significantly associated with treatment failure. Because of the collinearity of several variables significant in univariate regression analysis (HIV-l seropositivity, CD4 count, and plasma HIV-1 load), we did not create models adjusting for these confounding factors.

\section{DISCUSSION}

We found that the performance outcome of the syndromic STD treatment approach resulted in either undertreatment or overtreatment of STDs. In the primary care centre where the current study has been done, in the year 2000 alone, 9755 cases have been managed under the programme. ${ }^{4}$ Given the fact that more than $50 \%$ of the cases are misdiagnosed, the continued use of the current syndromic treatment approach is not warranted.

The underlying reason for the differential response to syndromic therapy might be attributed to the differences in the frequency of potentially untreatable or recurrent genital infections. Treatment failure of $61 \%$ in women with genital ulcer disease in our study is higher than the 19\% reported for Malawian men with genital ulcer disease. ${ }^{7}$ These might be attributed to differences in gender, genital ulcer disease aetiologies, drug susceptibility of the offending organisms, or differences in the stage of HIV infection. Indeed, the data support the contention that the effects of syndromic STD treatment depend on the prevalence of curable STDs in a given population. ${ }^{8}$ We have previously documented that herpes simplex virus type 2 (HSV-2) seroprevalence was strongly associated with history of genital ulcer syndrome $(\mathrm{OR}=5.32, \mathrm{CI}=2.39$ to $11.8, \mathrm{p}=0.0001)$ and HIV-1 seropositivity $(\mathrm{OR}=5.25, \mathrm{CI}=1.42$ to $19.35, \mathrm{p}=0.01)$ in women in Addis Ababa. ${ }^{10}$ Moreover, recent observation (Girma A et al, personal communication) showed that more than $75 \%$ of genital ulcerations among women are due to HSV-2. Treatment of HSV-2 is not included in the syndromic management algorithm of genital ulcer disease in Ethiopia. The association between HIV and genital ulcer disease caused by herpes may, therefore, be the reason for the failure of treatment rather than the presence of HIV alone. Moreover, a decrease in STDs following syndromic management ${ }^{11}$ may not result in parallel reduction in HIV prevalence in a given geographical setting. None the less, HSV-2 has become an important cause of genital ulcer disease in HIV infected people, ${ }^{7}$ thus antiherpes therapy should be included in syndromic management algorithms.

Earlier studies have shown that HIV infected men with concomitant STDs had increased shedding of HIV-1 and that effective treatment reduced HIV shedding. ${ }^{12}$ Whether syndromic treatment of STDs is effective in reducing HIV

Table 1 Distribution of laboratory diagnosed infection by syndromes

\begin{tabular}{|c|c|c|}
\hline \multirow[b]{2}{*}{ Laboratory diagnosed infection } & \multicolumn{2}{|c|}{ Syndromic STD diagnosis* $(n=106)$} \\
\hline & $\begin{array}{l}\text { Genital discharge } \\
(n=87)\end{array}$ & $\begin{array}{l}\text { Genital ulcer disease } \\
(n=19)\end{array}$ \\
\hline Neisseria gonorrhoeae & $11(12.7 \%)^{*}$ & $3(15.8 \%)$ \\
\hline Chlamydia trachomatis & $1(1.2 \%)$ & $0(0.0 \%)$ \\
\hline \multicolumn{3}{|l|}{ Bacterial vaginosis $\dagger$} \\
\hline Intermediate & 14 (16.1\%) & $3(15.8 \%)$ \\
\hline Moderate or severe & $22(25.3 \%)$ & $6(31.6 \%)$ \\
\hline Candida albicans & $14(16.1 \%)$ & $4(21.1 \%)$ \\
\hline Trichomonas vaginalis & $1(1.2 \%)$ & $0(0.0 \%)$ \\
\hline Active syphilisł & $10(11.5 \%)$ & $2(10.5 \%)$ \\
\hline \multicolumn{3}{|c|}{$\begin{array}{l}\text { *Only } 46 \% \text { had laboratory identified infections. } \\
\text { †Nugent's score: intermediate flora (score } 4-6 \text { ), and moderate or severe bacterial vaginosis }(7-10) .{ }^{5} \\
\text { fSeropositive by RPR and TPPA. } \\
11 \text { women with genital ulcer syndrome had additional genital discharge; and } 22 \% \text { and } 21 \% \text { women with genita } \\
\text { discharge and genital ulcer disease, respectively, had multiple laboratory identified infections. }\end{array}$} \\
\hline
\end{tabular}


Table 2 Risk factors associated with treatment failure of syndromic management of STDs $(n=96)$

\begin{tabular}{|c|c|c|c|c|}
\hline \multirow[b]{2}{*}{ Variables } & \multicolumn{2}{|c|}{ Treatment failure } & \multirow[b]{2}{*}{ OR $(95 \% \mathrm{Cl})$} & \multirow[b]{2}{*}{ Adjusted OR $(95 \% \mathrm{Cl})$} \\
\hline & No/total & $\%$ & & \\
\hline \multicolumn{5}{|l|}{ Clinical syndromes } \\
\hline Genital discharge & $22 / 73$ & 30.1 & $0.99(0.36$ to 2.73$)$ & - \\
\hline Cervicitis & $16 / 47$ & 34.0 & $1.43(0.60$ to 2.43$)$ & - \\
\hline Genital ulcer & $11 / 18$ & 61.1 & 5.24 (1.77 to 15.49$)$ & $4.12(1.35 \text { to } 12.58)^{*}$ \\
\hline Genital discharge and ulcer & $7 / 10$ & 70.0 & $6.79(1.61$ to 28.55$)$ & $5.06(1.17 \text { to } 21.84)^{*}$ \\
\hline Genital warts & $4 / 5$ & 80.0 & $10.56(1.13$ to 99.11$)$ & $7.81(0.82$ to 74.36$)$ \\
\hline \multicolumn{5}{|l|}{ Laboratory findings } \\
\hline HIV positive & $25 / 67$ & 37.3 & $3.72(1.16$ to 11.97$)$ & $2.46(0.71$ to 8.49$)$ \\
\hline Neisseria gonorrhoeae & $3 / 12$ & 25.0 & $0.74(0.19$ to 2.97$)$ & - \\
\hline Chlamydia trachomatis & $1 / 1$ & 100.0 & - & - \\
\hline \multicolumn{5}{|l|}{ Bacterial vaginosis $†$} \\
\hline Intermediate & $6 / 21$ & 28.6 & $1.44(0.44$ to 4.68$)$ & - \\
\hline Moderate or severe & $13 / 29$ & 44.8 & $2.93(1.06$ to 8.06$)$ & $1.27(0.42$ to 3.81$)$ \\
\hline Candida albicans & $6 / 15$ & 40.0 & $1.68(0.54$ to 5.26$)$ & - \\
\hline Trichomonas vaginalis & $0 / 1$ & 0.0 & - & - \\
\hline Active syphilis $\ddagger$ & $2 / 12$ & 16.7 & 0.42 (0.09 to 2.06$)$ & - \\
\hline Past syphilis & $5 / 23$ & 21.7 & $0.57(0.19$ to 1.71$)$ & - \\
\hline Cervical leucocytes ( $\geqslant 10 \mathrm{hpf}$ ) & $3 / 16$ & 18.8 & $0.48(0.13$ to 1.83$)$ & - \\
\hline \multicolumn{5}{|l|}{ CD4 count } \\
\hline$<200$ cells $\times 10^{6} / /$ & $11 / 27$ & 40.7 & $1.94(0.76$ to 4.97$)$ & - \\
\hline Per 100 cells $\times 10^{6} / /$ decrease & - & - & $1.18(1.00$ to 1.39$)$ & - \\
\hline \multicolumn{5}{|l|}{ Plasma HIV load } \\
\hline$\geqslant 10000$ copies $/ \mathrm{ml}$ & $22 / 50$ & 44.0 & 1.83 (1.04 to 3.22$)$ & $1.57(0.86$ to 2.87$)$ \\
\hline Per $\log _{10}$ copies $/ \mathrm{ml}$ increase & - & - & $3.67(0.94$ to 14.38$)$ & - \\
\hline
\end{tabular}

*Adjusted for HIV serostatus.

$\dagger$ Nugent's score: intermediate flora (score 4-6), and moderate or severe bacterial vaginosis (7-10). ${ }^{5}$

¥Seropositive by RPR and TPPA.

shedding in genital secretions is hardly known. Our preliminary results show that syndromic STD treatment failure can result in persistent genital shedding of HIV- $1 .{ }^{13}$ Its implication, however, remains to be addressed.

Although the WHO recommends syndromic treatment of STDs in developing countries at the primary healthcare level, ${ }^{3}$ accurate diagnosis and treatment of STDs is important in limiting the transmission of HIV infection. The recognition of treatable co-factors that may influence the sexual transmission of HIV will have important implications for HIV control programmes.

\section{ACKNOWLEDGEMENTS}

ENARP is a collaborative research project between EHNRI, the Amsterdam Municipal Health Service, the Central Laboratory of the Netherlands Red Cross Blood Transfusion Service, and the Academic Medical Centre of the University of Amsterdam. ENARP is a bilateral project financially supported the Netherlands Ministry of Foreign Affairs and the Ethiopian Ministry of Health. SM has also received financial support from the MASHAV, Jerusalem, Israel.

We thank the study participants for their kind collaboration, and the laboratory staff of ENARP and the microbiology section of EHNRI for their technical assistance.

\section{CONTRIBUTORS}

DW is the principal investigator responsible for all aspects of the study; ZG and ZM are co-investigators responsible for the clinical follow up of the patients and contributed to implementation of the study design; WD, HM, and ES are co-investigators and contributed to laboratory follow up, data entry, analysis, and writing of the manuscript; AG and WS were co-investigators who contributed to study research design, supervision of STD laboratory protocols, and write up; SM is co-principal investigator who contributed to the study design and write up; all investigators contributed to the editing of the final version of the manuscript.

\section{Authors' affiliations}

D Wolday, H Meles, T Messele, Ethio-Netherlands AIDS Research Project (ENARP), Ethiopian Health and Nutrition Research Institute (EHNRI), Addis Ababa, Ethiopia

Z G-Mariam, Department of Gynaecology and Obstetrics, Black-Lion Teaching Hospital, Addis Ababa, Ethiopia
Z Mohammed, Tekle-Haymanot Health Center, Addis Ababa, Ethiopia W Seme, A Geyid, Microbiology Section, Ethiopian Health and Nutrition Research Institute (EHNRI), Addis Ababa, Ethiopia

S Maayan, AIDS Center, Hadassah University Hospital, Jerusalem, Israel Conflict of interest: None.

Correspondence to: Dr D Wolday, Ethio-Netherlands AIDS Research Project (ENARP), Ethiopian Health and Nutrition Research Institute (EHNRI), PO Box 8297, Addis Ababa, Ethiopia; dawit@enarp.com

Accepted for publication 16 January 2004

\section{REFERENCES}

1 Kebede D, Aklilu M, Sanders E. The HIV epidemic and the state of its surveillance in Ethiopia. Ethiop Med J 2000;38:283-9.

2 Aklilu M, Messele T, Tsegaye A, et al. Factors associated with HIV-1 infection among sex workers of Addis Ababa, Ethiopia. AIDS 2001;15:87-96.

3 World Health Organization/Global Programme on AIDS. Management of sexually transmitted diseases, WHO/GPA/TEM/94.1. Geneva: WHO, 1994.

4 Médecins Sans Frontières, Belgium. Report on the implementation of syndromic case management in the public health centres of Addis Ababa, Ethiopia, Addis Ababa, 2000.

5 Médecins Sans Frontières (Belgium)/Addis Ababa Health Bureau Joint Initiative. Sexually transmitted diseases syndrome therapeutic guidelines, Addis Ababa, 1999

6 Nugent RP, Krohn MA, Hillier SL. Reliability of diagnosing bacterial vaginosis is improved by a standardized method of gram stain interpretation. J Clin Microbiol 1991;29:297-301.

7 Behets FM, Liomba G, Lule G, et al. Sexually transmitted diseases and human immunodeficiency virus control in Malawi: a field study of genital ulcer disease. J Infect Dis 1995;171:451-5.

8 Grosskurth H, Mosha F, Todd J, et al. Impact of improved treatment of sexually transmitted diseases on HIV infection in rural Tanzania: randomised controlled trial. Lancet 1995;346:530-6.

9 Wawer MJ, Sewankambo NK, Serwadda D, et al. Control of sexually transmitted diseases for AIDS prevention in Uganda: a randomised community trial. Lancet 1999:353:525-35.

10 Mihret W, Rinke de Wit TF, Petros B, et al. Seroprevalence of herpes simplex virus type-1 (HSV-1) and type-2 (HSV-2) among urban and semiurban Ethiopians: possible association with HIV status and sociodemographic factors. Sex Transm Dis 2002:175-81.

11 Corbett EL, Stekette RW, Kuile FO, et al. HIV-1/AIDS and the control of other infectious diseases in Africa. Lancet 2002;359:2177-87.

12 Coombs RW, Reichelderfer PS, Landay AL. Recent observations on HIV type- 1 infection in the genital tract of men and women. AIDS 2003;17:455-80.

13 Wolday D, GebreMariam Z, Mohammed Z, et al. The impact of syndromic treatment of sexually transmitted diseases on cervical shedding of HIV-1. AIDS 2004;18:781-5. 